\title{
Anterior omuz instabilitesi: Akut ilk çıkık
}

\author{
Anterior shoulder instability: the first acute dislocation
}

\author{
Mustafa Karahan
}

Marmara Üniversitesi Tıp Fakültesi Ortopedi ve Travmatoloji Anabilim Dalı, İstanbul

\begin{abstract}
İnsan vücudunda en sık çıkığın gözlendiği eklem glenohumeral eklemdir. Bu çıkık \%96 oranında travma sonucu oluşsa da \%4 atravmatik olabilir; genellikle, tekrarlayan omuz çıkığı ile sonuçlanmaktadır. Tekrarlayan omuz çıkığının insidansı, genç sporcularda ilk çıkı̆̆ı takiben \%90 oranında olabilmektedir. Bu oranı etkileyen faktörler hastanın ilk çıkık anındaki yaşı, çıkığa eşlik eden kemik ve yumuşak dokuya ait patolojik bulgular, uygulanan tedavi protokolü ve hastanın sportif aktivitesidir. Omuz çıkıkları ile, özellikle hentbol, voleybol, yüzme ve güreş gibi sporlarda karşılaşılmaktadır.
\end{abstract}

Anahtar sözcülkler: omuz; eklem instabilitesi; çıkıklar
The most common dislocation observed in the human body is at the glenohumeral joint. This dislocation occurs in $96 \%$ of the cases as a result of trauma whereas $4 \%$ of them may be atraumatic, often resulting in recurrent dislocation of the shoulder. The incidence of recurrent shoulder dislocation is $90 \%$ in young athletes. The factors affecting this rate are: age of the patient at the time of the first dislocation, pathological findings of the bone and soft tissue accompanied by dislocation, treatment protocol, and sportive activities of the patient. Shoulder dislocations are encountered particularly in sports such as handball, volleyball, swimming, and wrestling.

Key words: shoulder; joint Instability; dislocations

\section{GENEL BILGILER}

\section{Omuz anatomi ve biyomekaniği}

Glenohumeral eklemin kimi günlük hareketler ve çoğu üst ekstremite sportif hareketlerinin gerektirdiği düzeyde mobil olabilmesi için zaman zaman stabilitesinin sınırlarının zorlanması gereklidir. Eklemin stabilitesi statik ve dinamik faktörlere bağlıdır. Statik faktörler kemiksel yapı, kıkırdak, glenoid labrum ve glenohumeral ligamentler ve kapsüldür. Glenoid kıkırdağın perifere gittikçe kalınlaşması ve labrum ile desteklenmesi sayesinde glenoid konkavitesi sağlanır. Kapsül ve ligamentler, eklemin tüm hareket açıklığının çoğunda gevşek olup, eklem hareket açıklığının sınırında gerilirler. Stabiliteye katkıda bulunan diğer faktörler, kıkırdak yüzeyler arasında adhezyon/kohezyon etkisi ve negatif eklem-içi basınçtır.

\section{Çıkık patofizyolojisi}

Omuza binen yükler omuz stabilitesini sağlayan unsurların gücünü aştığında omuz çıkar. Omuzun akut

öne çıkığı, çoğunlukla abduksiyon, ekstansiyon ve dış rotasyon sonucu humerus başının anterior kapsül ve labrumu zorlayarak glenoidden taşması ile oluşur. Nadir olarak, omuza posteriordan uygulanan kuvvet sonucu da omuz öne çıkabilir. Kroner ve ark.'nın çaIışmasına göre, omuz çıkıkları yaşılarda en çok evde, gençlerde ise daha çok spor salonları veya topluma açık alanlarda oluşmaktadır. ${ }^{[1]}$ Aynı çalışmada, yaralanma mekanizması olarak en sık omuz üzerine düşme tespit edilmişken, onu açık kol üzerine düşme takip etmektedir.

Çıkıklar akut (iki haftaya kadar olan çıkıklar) veya kronik (daha sonrasında başvurursa) olabilir. Çıkıklar tekrarlayabilir. Travmatik çıkıklarda mutlaka bir travma ve yaralanma öyküsü vardır. Atravmatik çıkıklarda ise omuz çok az veya hiç travma olmaksızın çıkar; bazen de istemeden çıkabilir veya hasta isteyerek çıkarır. İstemsiz atravmatik çıkıklı hastalarda genellikle kollajen bozuklukları, konjenital malformasyonlar veya nöromusküler hastalıklara rastlanır. İstemli atravmatik çıkıklı hastalarda psikolojik sorunlar ön plana çıkabilir.

- Illetişim adresi: Prof. Dr. Mustafa Karahan, Op. Dr. Cemil Topuzlu Cd. No: 37/2, 34726 Fenerbahçe, Kadıköy, İstanbul Tel: 0532 - 2857054 e-posta: drmustafakarahan@yahoo.com

- Geliș tarihi: 25 Haziran 2013 Kabul tarihi: 25 Ekim 2013 


\section{Omuz çıkığında görülen patolojiler}

Travmatik anterior omuz çıkığı eklem bütünlüğünü zedeler. Anterior inferior glenohumeral ligament, anteroinferior labrum ve inferior kapsülden oluşan anteroinferior kapsülolabral kompleks, omuz abduksiyon ve eksternal rotasyonda iken anteriora translasyonu engelleyen en önemli yapıdır. Öne omuz çıkığı sonrasında omuzların \%85-97'sinde labrum glenoidin anteroinferiorundan ayrılır. Bankart lezyonu adı verilen bu patoloji bazen kemik ile birlikte olur ve "kemikli Bankart" adını alır. Anterior labrum, öne doğru yüklenmelerde karşı koyan birincil yapı olduğundan anterior çıkıklarda en çok hasarlanan yapıdır.

Diğer bir lezyon olan HAGL (Humeral avulsion of the glenohumeral ligament) lezyonu ise humerus başından inferior glenohumeral ligamentin avulsiyonunu tanımlar. Yaş ilerledikçe eşlik eden rotator cuff yırtığı oranı da artar. 20 yaş altında nadir iken, 40 yaş üstünde \%30'a, 60 yaş üstünde ise \%80'e yükselir. Omuz çıkığına eşlik eden tüberkulum majus kırıkları ise, 30 yaş üstündeki hastalarda daha sık görülmektedir.

Humerus başının öne yüklenmesi ile birlikte pektoralis minör kası aksiller arter üzerine basar. Gençlerde sık olmayan damar yaralanması yaşlılarda daha çok görülür. Damar yaralanmasından şüpheleniliyorsa damar yolu açılıp, kan hazırlatılarak ve damar cerrahı da sürece dahil edilerek acil olarak tedavi planlanmalıdır.

Nörolojik yaralanmalar tüm olguların \%45 kadarında rapor edilmektedir. En sık görülen aksiller sinir lezyonunda, inervasyon alanında duyusal etkiler oluşur ve tanı yaralanma sonrası 3.-4. haftalarda EMG ile doğrulanabilir. Redüksiyon sonrası düzelme için 3 ay gözlem gerekebilir.

\section{KLINIK DEĞERLENDIRME}

Omuz öne çıkıklarında yoğun ağrı ve hareketsizlik olur. Humerus başı omuz anteriorunda şişlik olarak gözle görülebilir, palpe edilebilir. Omuzun normal görüntüsü kaybolmuş, omuz oval hattını yitirmiştir. Omuzu çıkmış hasta kolunu hafif dış rotasyonda ve diğer eliyle dirsekten destekleyerek hafif abduksiyonda tutarak taşır.

Omuz çıkıklarında, kemik patolojilerinin yanında sinir yaralanmaları da ekarte edilmelidir. Bu açıdan nörolojik muayene önemlidir. En sık nörolojik artsorun, aksiler (sirkumfleks) sinir palsisidir ve proksimal humerusun lateral bölgesinde duyu kusuru olup olmadığı iğne batırma (pin prick) testi ile araştırılmalıdır. Omuz çıkıklarında posterior kordun radial dalı da etkilenebileceğinden, el bileği aktif dorsifleksiyon hareketi kontrol edilerek radyal sinir muayenesi yapılmalıdır. Dolaşım açısından aksiler arter nabız kontrolü yapılmalıdır.
Tanı genellikle hastanın omuzunun çıkmış halinin görülmesi, palpe edilmesi ve hastanın nasıl çıktığını anlatmasıyla konur. Direkt anteroposterior (AP) grafi ile tanı kesinleşir ve kemiklere ilişkin bir patoloji olup olmadığı da aynı grafı ile anlaşılabilir. Bazen dislokasyon esnasında humerus başının posterior yüzü ile glenoidin anterior yüzünün çarpışması sonucu, humerus başının posterior yüzünde çökme kırı̆gı (Hill-Sachs defekti) meydana gelebilmektedir. Omuzun öne çıkıklarında tuberositi major kırıklarına da rastlanabilmektedir. Çıkık yönünün AP grafi ile anlaşılamadığında ya da şüphede kalındığında, ikinci bir grafi olarak aksiyel lateral, apikal oblik ya da transtorasik grafiler yardımcı olabilir.

\section{TEDAVi}

\section{ilk müdahale}

Omuz çıkığı acil olarak redükte edilmesi gereken bir durumdur. Ancak dikkat edilmesi gereken önemli iki nokta vardır. Birincisi, redükte etmek için aşırı güç uygulayarak bir kırığa yol açmaktan kaçınmak, ikincisi ise herhangi bir sinir zedelenmesine neden olmamaktır. Hastanın telkin yoluyla veya ilaç yoluyla sakinleştirilmesi çıkık omuzun redükte edilmesinin ilk aşamasıdır. Omuzun akut çıkığı standart metodların biriyle redükte edilmelidir. Redüksiyon sağlandıktan sonra düz grafilerle redüksiyonun yeterliliğini değerlendirmek için görüntüleme yapılmalıdır.

\section{Karşı traksiyon yöntemi}

Sık olarak kullanılan bir teknik traksiyonla karşı traksiyon uygulanmasıdır. Ters tarafın skapula gövdesinin hizasından gövdenin etrafından dolandırılmış bir çarşaf çekilirken onun karşısından disloke olmuş kola sürekli ve sabit traksiyon uygulanır. Yorulan kaslar ve azalan humerus başını kilitleyen spazmlarla nazik bir manipülasyon omuzun redüksiyonunu sağlar.

\section{Koher yöntemi}

Diğer sık kullanılan bir yöntemdir. Traksiyon ile eş zamanlı dış rotasyon yapılır. Bu işlem yavaşça devam ettirilir ve kendiliğinden redüksiyon olması için iki dakika beklenir. Eğer redüksiyon olmazsa dirsek göğsün üzerine konur ve el karşı omuzun üzerine iç rotasyon verilerek getirilir. Bu manevra esnasında redüksiyon beklenir.

\section{Stimson yöntemi}

Bir diğer metod olan Stimson manevrasında ise, doktor hastayı yüz üstü bir şekilde yatırıp etkilenmiş kolu muayene masasının kenarından aşağı sarkıtır. Kola bağlanan yaklaşık 4 kg ağırlıkla traksiyon sağlanır. 
Yaklaşık 5-6 dakika içinde kendiliğinden redüksiyon beklenir fakat redüksiyon gerçekleşmez ise, çeşitli manipülasyonlarla (bir elle skapula superomedialini sabitleyip diğer elle inferior kutbu mediale ittirmek) redüksiyon sağlanır.

\section{Milch yöntemi}

Milch metoduna göre, omuz eklemine yavaşça abduksiyon uygulanır ve kola aynı hızda dış rotasyon verilir. Abduksiyonun sonuna gelindiğinde redüksiyon halen sağlanmadıysa, birinci parmak ile humerus başına bastırılarak, humerus başının glenoid üzerinden atlaması sağlanır.

\section{Hipokrat yöntemi}

Omuz redüksiyonunun bilinen ilk metodu Hipokrat tekniği ise, kola traksiyon uygularken aynı zamanda koltuk altına konan topuk ile gövdeyi karşı yönde itmek ve kolu adduksiyona getirmektir.

\section{İnstabilite tedavisi}

İlk müdahale yapıldıktan sonra kalıcı tedavi planlanmalıdır. Tedavinin amacı, herhangi bir ek patoloji yaratmadan omuzun yeniden çıkmasına engel olmaktır. Kol daha sonrasında immobilizasyon amaçlı bandaja alınır. Ne yazık ki ağrısı geçen, kendisini iyi hisseden, yürüyebilen hastalar ve sporcular hemen tespitten kurtulmak eğilimindedirler. Bir çalışmada ilk çıkık sonrası tekrar çıkık $30-40$ yaş aralığında \%10 oranında bulunurken 20 yaş altında bu oran \%33 bulunmuştur. ${ }^{[2]}$ Literatürde, genç aktif erkeklerde ilk çıkık sonrası tekrar çıkık oranının \% 80'lere çıktığını öne süren çalışmalar vardır.

Bandaj erken çözüldüğü zaman yeniden çıkma riski vardır. Bu kadar uzun süreli tespitin uygulanmaması durumunda glenoid labrumun tam iyileşmesi olmayacağı için omuzda kronik instabilite gelişebilir.

\section{Konservatif tedavi}

Öncelikle yaş grubu ve sonrasında var olan patolojilerin değerlendirilmesi sonucunda hastaya konservatif tedavi uygulanmaya karar verildiyse omuz tespite alınır. Literatürde, omuz çıkığı sonrasındaki tespit posizyonu konusunda çeşitli görüşler mevcuttur.

iç rotasyonda tespit: Hipokrattan bu yana, omuz çıkıklarından sonra omuz geniş bir askının içinde kol gövdenin yanında iken iç rotasyonda tutulmaktadır. Bu yöntem kendi başına herhangi bir bilimsel gerekçeye dayanmamaktadır, ancak uygulama kolaylığı ve rahatlığı vardır. Her ne kadar 4-6 hafta süreli tespit çok yaygın olarak önerilen süre olsa da, Hovelius ve ark., ${ }^{[3]}$ iç rotasyonda tespit süresi 1 hafta olan hastalarla 3-4 hafta olan hastaları karşılaştırdıklarında, tekrar çıkık oranları açısından bir fark bulamamışlardır.

Dış rotasyonda tespit: Omuzun tekrar çıkmaması için, çıkık sırasında ayrılan dokuların karşııılı olarak tespit edilmeleri ve uygun gerilimde iyileşmeleri gerekmektedir. Itoi ve ark. ${ }^{[4]}$ omuzun dış rotasyonda tespit edilmeleri ile subskapularis kasının ayrışan kapsüloligamentöz yapı üzerinde bası oluşturduğunu öne sürerek, klasik yöntemlerle tespit edilen omuzlara göre tekrarlama oranının daha düşük olduğunu göstermişlerdir. Bu metodla immobilizasyon nispeten pahalı olup hantal bir ortez kullanımı içerdiği için, hastaların uyum oranı önemli ölçüde düşmektedir. Aynı çalışmada, sadece iki günlük bir gecikmenin bile bu yöntemin etkinliğini azaltacağı belirtilmiştir. ${ }^{[4]}$ Daha sonra yapılan kimi çalışmalar, tespit açısı konusunda kesin bir yön verememiştir. ${ }^{[5]}$ Sonuç olarak, dış rotasyon açısının miktarı, tespitin süresi gibi önemli noktalar konusunda kanıtlanmış bir bilgi yoktur.

Immobilizasyon sonrası rehabilitasyon: Omuz tespiti sırasında dirsek, el bileği ve el eklemlerinin hareketliliğinin sürdürülmesi gereklidir. Süresi ne kadar olursa olsun, omuz tespiti sonrasında eklem hareket genişliği, gücü ve fonksiyonlarında azalma olacaktır. Tespit süresi sonunda hastalar rotator cuff güçlendirme ve skapular stabilite egzersizlerini de içeren fizyoterapi programına alınmalıdır.

Erken harekete başlanması, kolun tüm hareketlerini tehlikeye atacak olan yapışıklıkların oluşmasını engeller. Rehabilitasyon, skapula stabilizasyon egzersizlerine önem verirken, omuz ekleminin dinamik stabilizatörleri olan rotator manşet ve deltoid kasın güçlendirmesini de içermelidir. Yüzme, omuzun güçlendirilmesi ve proprioseptif kontrolün sağlanması için 6 . haftadan sonra çok yararlı olacaktır. Omuzun tam hareket açılığına ulaşması, güç ve stabilite hissini kazanması üç ayı bulacağından, spora dönüşe bu dönemden sonra izin verilir.

\section{Cerrahi tedavi}

Omuzun tekrar çıkması hasta için sadece ağrı ve üzüntü kaynağı değildir. Sporcular gibi üst ekstremitesini kullanarak hayatını kazananlar için gelir kaybına, sportif faliyetlerde güven kaybına ve post-travmatik osteoartrite yol açabilir. Bir omuz çıkığı sonrası osteoartrit gelişme riski normal bir omuza göre 20 kat daha fazladır ve çıkık sayısı arttıkça risk artmaktadır. illk omuz çıkığı sonrasında tedavi yöntemi kararını, hasta ile birlikte seçilecek tedavi yöntemlerinin yinelenme oranlarını ve cerrahi tedavi sonrasında oluşacak artsorun olasılıklarını gözönünde bulundurarak vermek gerekir. 
Artroskopik anterolabral rekonstrüksiyon: Günübirlik cerrahi tedavi avantajı olan artroskopik teknikler ameliyat sonrası ağıı ve sertliği azaltıp kozmetik ve hızlı bir iyileşme sağladığı için, özellikle kontakt sporlarla uğraşan genç erkekler gibi yüksek yinelenme riski olan hastalarda, primer stabilizasyon için önerilmektedir. Bu yüksek riskli hasta grubunda birincil artroskopik stabilizasyonun konservatif tedavi ile karşılaştırıldığında yineleyen instabilite oranını azaltıp yaralanma öncesi aktivite ve spora geri dönüş oranını yükselttiğine dair günümüzde artan kanıtlar mevcuttur. Ancak artroskopik teknikler izole Bankart lezyonlarının tedavisinde çok etkili olmasına rağmen, glenoid rim kırıkları ve büyük Hill-Sachs defektlerinde başarı oranı düşüktür.

\section{YAZARLARIN UYGULAMALARI}

İlk dislokasyon sonrasında cerrahi girişim halen tartışma konusu olmaya devam etmektedir. Kirkley ve ark. akut ilk çıkık durumunda üç hafta immobilizasyon ve bitiminde rehabilitasyon tedavisini ilk dört hafta içinde yapılan artroskopik Bankart tamiri ile tek kör bir çalışmada kıyasladıklarında; ilk dört haftada artroskopik girişim uygulanan hastaların omuz stabilitesinin immobilizasyon ile takip edilen hastalara göre daha iyi, fakat her iki grupta da omuz hareket açıklığının benzer olduğuna rastlamışlardır. Bu nedenle, akut ilk çıkıkta cerrahi ya da konservatif tedavi her hastanın kendisine ve hayattaki beklentilerine göre şekillendirilmelidir. Yirmi beş yaş altı, aktif spor ile uğraşan hastalarda tercih cerrahiden yana olmalıyken, 40 yaş üstü hastalarda konservatif davranmayı tercih ediyoruz.

\section{KAYNAKLAR}

1. Krøner $K$, Lind $T$, Jensen J. The epidemiology of shoulder dislocations. Arch Orthop Trauma Surg 1989;108(5):288-90.

2. Hovelius L. The natural history of primary anterior dislocation of the shoulder in the young. J Orthop Sci 1999;4(4):307-17.

3. Hovelius L, Augustini BG, Fredin H, Johansson $\mathrm{O}$, Norlin R, Thorling J. Primary anterior dislocation of the shoulder in young patients. A ten-year prospective study. J Bone Joint Surg Am 1996;78(11):1677-84.

4. Itoi E, Hatakeyama $Y$, Sato T, Kido T, Minagawa H, Yamamoto N, Wakabayashi I, Nozaka K. Immobilization in external rotation after shoulder dislocation reduces the risk of recurrence. A randomized controlled trial. J Bone Joint Surg Am 2007;89(10):2124-31.

5. Liavaag S, Brox JI, Pripp AH, Enger M, Soldal LA, Svenningsen $S$. Immobilization in external rotation after primary shoulder dislocation did not reduce the risk of recurrence: a randomized controlled trial. J Bone Joint Surg Am. 2011;93(10):897-904. CrossRef 